\title{
Emergência de plântulas de Copernicia alba (Morong ex Morong e Britton) em função da escarificação mecânica e imersão de sementes em água corrente ${ }^{(1,2)}$
}

\author{
CARMEM LÚCIA FERREIRA FAVA ${ }^{(3)}$, MARIA CRISTINA FIGUEIREDO E ALBUQUERQUE(4)
}

\author{
RESUMO
}

\begin{abstract}
Este trabalho teve como objetivo avaliar a emergência de plântulas de Copernicia alba em função da escarificação mecânica e imersão das sementes em água corrente. As sementes foram submetidas a duas formas de escarifição mecânica - escarificação na região do hilo e escarificação na região e no lado oposto ao hilo - e a três tempos de imersão em água corrente - 24, 48 e 72 horas. Os tratamentos foram comparados com testemunhas sem escarificação e sem embebição. A escarificação mecânica foi feita manualmente com uma lixa $\mathrm{n}^{\circ} 100$. O delineamento experimental foi o inteiramente casualizado, em esquema fatorial $3 \times 4$, com quatro repetições de 20 sementes. Os dados foram submetidos à análise de variância e as médias comparadas pelo teste Tukey a 5\% de probabilidade. A causa da dormência em sementes de Copernicia alba é de natureza física, sendo devida à dureza de seu endocarpo. A escarificação mecânica não foi eficiente para acelerar a emergência de plântulas, e a imersão das sementes em água corrente por 24 ou 48 horas foi eficaz para a superação da dormência em sementes desta espécie.
\end{abstract}

Palavras-chave: Arecaceae, carandá, palmeira, dormência.

\section{ABSTRACT \\ Emergence of Copernicia alba (Morong ex Morong and Britton) seedlings in function of mechanical scarification and seed immersion in running water}

\begin{abstract}
This study aimed to evaluate the emergence of Copernicia alba seedlings in function of mechanical scarification and seed washing in running water. The Seeds were submitted to two forms of mechanical escarification (scarification in the region of hilum and scarification in the and region the opposite side to hilum) and three times of immersion in current water (24, 48 and 72 hours). The treatments were compared with controls (without scarification and without immersion). Scarification mechanical was performed manually with assists of no 100 sandpaper. After treatment, seeding was performed on sand substrate. A completely randomized experimental design was adopted, in a $3 \times 4$ factorial combination, with four replicates of 20 seeds. The data were submitted to analysis of variance and the means were compared by Tukey's test at 5\% probability. The cause of dormancy in Copernicia alba seeds is physical in nature, due to the hardness of its endocarp. The scarification mechanics was not efficient to speed up the emergence of seedlings and is immersion of the seeds of $\mathrm{C}$ alba in running water for 24 or 48 hours was efficient to overcome dormancy in seeds of this species.
\end{abstract}

Keywords: Arecaceae, caranday, palm, dormancy.

\section{INTRODUÇÃO}

Todas as palmeiras são consideradas ornamentais, embora algumas sejam amplamente utilizadas e outras totalmente desconhecidas, tendo potencial para serem usadas no artesanato, como alimento, na produção de óleo, cera, entre outras. As palmeiras têm ainda grande importância ecológica, principalmente no fornecimento de alimento para a fauna silvestre, possibilitando sua sobrevivência (PIVETTA et al., 2007).

Copernicia alba (Morong ex Morong \& Britton), popularmente conhecida como carandá, pertence à família Arecaceae. O nome do gênero é uma homenagem ao astrônomo italiano Copérnico, que concluiu ser a forma da terra globosa, em alusão a essa forma apresentada pela copa da planta. A palmeira carandá é muito elegante e pode ser utilizada no paisagismo (POTT e POTT, 1994).

Essa palmeira apresenta tronco único, de $8-30 \mathrm{~m}$ de altura, estipe reto e cilíndrico, folhas numerosas, em leque, palmadas, de cor verde clara quando jovem. Inflorescências dispostas entre folhas e posicionadas mais ou menos verticalmente, ramificadas e excedendo o comprimento das folhas, frutos ovoides e pretos (LORENZI et al., 2004).

Ocorre em Mato Grosso e Mato Grosso do Sul (Pantanal), em terrenos periodicamente inundados, onde forma populações homogêneas denominadas carandazais, constituídos por um estrato arbóreo formado quase exclusivamente pela palmeira carandá $(C . a l b a)$ e estratos arbustivo e herbáceo variáveis (SILVA et al., 1998).

A área estimada de carandazais para a vegetação pantaneira é de $2,3 \%$, sendo a segunda formação monotípíca mais representativa. O carandá também é encontrado em fitofisionomias denominadas mata mista, onde são encontradas espécies de mata semidecíduas, associadas ao paratudo (Tabebuia aurea (Manso) B. e H.) (SILVA et al., 2000).

As palmeiras são propagadas quase que exclusivamente por sementes, embora apresentem germinação lenta, desuniforme e frequentemente em baixa porcentagem para a maioria das espécies, perdendo a viabilidade rapidamente quando desidratadas (BROSCHAT, 1994). Diferentes espécies de palmeiras têm comportamento típico de

\footnotetext{
(1) Recebido em 04/11/2009 aceito para publicação em 20/05/2011.

(2) Parte da dissertação de Mestrado da primeira autora, financiada pelo CNPq

${ }^{(3)}$ Doutoranda da Universidade Federal do Mato Grosso.

(4) Professor Associado da Universidade Federal do Mato Grosso.
} 
sementes recalcitrantes e não toleram a dessecação até determinados graus de umidade considerados relativamente elevados, tidos como letais para a semente (STRINGHETA et al., 2004).

Sementes de palmeiras normalmente apresentam dormência física, devido à dureza de seu endocarpo, que impede a embebição de água. O embrião muitas vezes parece dormente, mas continua crescendo, embora vagarosamente (LORENZI et al., 2004).

Para sementes de tucumã (Astrocaryum aculeatum), a dormência pode estar relacionada, em parte, ao endocarpo pétreo que as envolve, dificultando a embebição de água, restringindo a difusão de oxigênio e/ou impondo resistência mecânica ao crescimento do embrião e à subsequente emergência da plântula (FERREIRA e GENTIL, 2006)

A embebição prévia das sementes por determinado período é suficiente para promover a germinação quando existe impermeabilidade do tegumento. Porém, dependendo da espessura e da permeabilidade do tegumento, considerase o uso de ácidos como meios para superação de dormência (TAKAHASHI et al., 2006). Também pode ser usada a escarifição mecânica por abrasão da superfície, até que o endosperma fique visível.

Segundo PIVETTA et al. (2007), para se ter ideia da viabilidade das sementes, é comum colocá-las imersas em água e as que flutuam são descartadas como inviáveis; entretanto, algumas sementes de palmeiras flutuam naturalmente, porque são disseminadas na natureza pela água. A pré-embebição tem sido empregada para superação de dormência de sementes dessas espécies, com imersão em água por 1 a 7 dias, trocando a água diariamente. Embora seja um tratamento que não causa danos à semente, quando comparado a outros utilizados na quebra de dormência, nota-se que nem todas as espécies respondem a ele.

O desenvolvimento das estruturas básicas do processo germinativo é bastante peculiar na família Arecaceae, podendo diferir entre espécies; desta forma, o conhecimento dos estádios morfológicos durante a germinação das sementes de cada espécie de palmeira é imprescindível para auxiliar na análise do ciclo vegetativo, podendo fornecer subsídios à interpretação de testes de germinação e, também, auxiliar os estudos de taxonomia e ecologia (KOBORI, 2006).

Nas Regras para Análise de Sementes - RAS (BRASIL, 1992), revalidadas pela Instrução Normativa $N^{\circ} 19$, de 18 de outubro de 2005 (MAPA, 2005), são relatados procedimentos de análise para várias espécies vegetais; no entanto, há escassez de informações sobre germinação de sementes de palmeiras, constando apenas a espécie juçara (Euterpe edulis) nas RAS.

O objetivo neste trabalho foi avaliar a emergência de plântulas de Copernicia alba em função da escarificação mecânica e imersão das sementes em água corrente.

\section{MATERIAL E MÉTODOS}

O presente estudo foi conduzido no Laboratório de Sementes da Faculdade de Agronomia e Medicina Veterinária da Universidade Federal de Mato Grosso Campus de Cuiabá, com sementes de Copernicia alba (Morong ex Morong e Britton). Os frutos foram coletados de três exemplares existentes em área urbana na cidade de Cuiabá-MT, situada nas coordenadas 15\%36'29"S e $56^{\circ} 45^{\prime} 16^{\prime \prime} \mathrm{W}$, nos meses de abril e maio de 2007. Após a coleta, os frutos foram encaminhados ao Laboratório de Sementes para remoção do epicarpo e do mesocarpo por meio de atrito manual e depois foram homogeneizados manualmente.

As sementes foram submetidas à análise de teor de água pelo método de estufa a $105^{\circ} \mathrm{C} \pm 3^{\circ} \mathrm{C}$ por 24 horas, utilizando-se oito subamostras de 100 sementes, tendose calculado a massa de mil sementes (BRASIL, 1992). Posteriormente, foram acondicionadas em sacos de papel Kraft, em câmara refrigerada $\left(18^{\circ} \mathrm{C} \pm 2^{\circ} \mathrm{C}\right.$ e $73 \% \pm 4 \%$ UR), por 30 dias, quando da realização dos experimentos.

$\mathrm{O}$ delineamento experimental foi o inteiramente casualizado, em esquema fatorial $3 \times 4$, sendo duas formas de escarificação mecânica (escarificação na região do hilo e escarificação na região e lado oposto ao hilo) e a testemunha (sem escarificaçao) e três tempos de imersão em água corrente (24, 48 e 72 horas) e sem imersão (0) com quatro repetições de 20 sementes. Para a escarificação mecânica, foi utilizada lixa d'água $\mathrm{n}^{\mathrm{O}} 100$, sendo que a área escarificada por semente foi de 3 a $4 \mathrm{~mm}$ na região e oposto ao hilo. Após a escarificação, as sementes foram colocadas imersas em água corrente por 0, 24, 48 e 72 horas.

Após os tratamentos, as sementes foram colocadas em caixas de plástico com dimensões de $20 \mathrm{~cm}$ x $30 \mathrm{~cm}$ x $9 \mathrm{~cm}$. A profundidade de semeadura foi aproximadamente $1,5 \mathrm{~cm}$. O substrato utilizado foi areia esterilizada e umedecida com a quantidade de água equivalente a $60 \%$ da capacidade de retenção do substrato (BRASIL, 1992), tendo sido efetuadas regas sempre que necessário. O experimento foi mantido em condições de laboratório com temperatura ambiente entre $25^{\circ} \mathrm{C}$ e $27^{\circ} \mathrm{C}$, umidade relativa em torno de $58 \%$ e oito horas de luz diária.

A emergência das plântulas foi monitorada diariamente até a estabilização aos $90^{\circ}$ dia após a semeadura. Foram calculados o tempo médio de emergência (LABORIAU, 1983), o índice de velocidade de emergência (MAGUIRE, 1962) e a porcentagem de emergência das plântulas. As plântulas foram consideradas emergidas após a emissão do primeiro eófilo acima do substrato areia.

As análises estatísticas foram realizadas com os dados originais, pois atenderam às pressuposições da homogeneidade de variâncias e da normalidade dos resíduos. Os dados foram submetidos à análise de variância e as médias comparadas pelo teste Tukey a 5\% de probabilidade e regressão polinomial, conforme metodologia descrita por RIBEIRO JUNIOR (2001), utilizando-se o software SAEG (1993).

\section{RESULTADOS E DISCUSSÃO}

Os valores médios do teor de água e da massa de mil sementes de Copernicia alba foram 44,3\% e 997,26g, respectivamente.

TOMLINSON (1961) citou três tipos de germinação em sementes de palmeiras: remota tubular, remota ligulada e adjacente ligulada. Em sementes de Copernicia alba foi verificado que a germinação é do tipo remota tubular, ou seja, nesse tipo de germinação, o alongamento do pecíolo 
cotiledonar é marcante.

A primeira estrutura emitida foi o botão germinativo, que QUEIROZ (1986) propõe como critério de emergência em sementes de juçara (Euterpe edulis Mart.). Em seguida, surgiu o pecíolo cotiledonar que, em geral, é erroneamente confundido com a raiz (PIVETTA et al., 2007). A emissão do eófilo ocorreu com o rompimento da bainha, permitindo a emergência da plúmula, que apareceu entre o $41^{\circ}$ ao $90^{\circ}$ dias após a semeadura.

$\mathrm{Na}$ avaliação das plântulas, as raízes primárias não puderam ser avaliadas quanto à direção do crescimento ou a torções, pois a profundidade das caixas utilizadas na semeadura não permitiu crescimento livre dessas estruturas.

Os resultados de porcentagem, tempo médio e índice de velocidade de emergência de plântulas de $C$. alba, em função das formas de escarificação mecânica, estão apresentados na Tabela 1. Não ocorreu efeito da interação escarificação $\mathrm{x}$ tempo de imersão sobre a emergência de plântulas $(\mathrm{P}>0,05)$. Também não foi verificado efeito da escarificação sobre as características avaliadas.

O tempo de imersão das sementes em água corrente influenciou a porcentagem e o Índice de Velocidade de Emergência das plântulas (Figura 1). O tempo médio de emergência foi de 56 dias e não ocorreu variação entre os tempos de imersão. Provavelmente, algumas substâncias que inibiam a germinação tenham sido eliminadas quando as sementes foram imersas em água corrente por 24 e 48 horas, tendo sido os índices de velocidade (Figura 1) e porcentagens de emergência das plântulas (Figura 2) mais elevados do que a testemunha.

O tempo de germinação das sementes de palmeiras é variável: para as sementes de C. alba, é em média de 40 dias; na palmeira-leque (Washingtonia robusta), ocorre em menos de 15 dias; em sementes de tamareira-de-jardim (Phoenix roebelenii), em três dias; para areca-bambu (Dypsis lutescens), em torno de 25 dias; e sementes de camedórea-elegante (Chamaedorea elegans) podem demorar meses para iniciar a germinação (PIVETTA et al., 2007).

A água é um método eficiente para obter maiores taxas de germinação para as sementes da palmeira licuri (Syagrus coronata), tendo sido verificado que a embebição em água por um período de 24 e 48 horas resultou em altas taxas de germinação das sementes (CARVALHO et al., 2005).

A equação de regressão ajustada para o teste de emergência das plântulas em função do tempo de imersão é apresentada na Figura 2. As sementes apresentaram comportamento quadrático em relação a essa variável: os maiores valores foram observados com 24 horas de imersão, diminuindo progressivamente para 48 e 72 horas. Os menores valores foram observados quando não foi utilizada a imersão (Figura 2).

Com a absorção de água por embebição, ocorre a reidratação dos tecidos e, consequentemente, a intensificação da respiração e de todas as outras atividades metabólicas, que resultam no fornecimento de energia e nutrientes necessários para a retomada de crescimento por parte do eixo embrionário. Por outro lado, o excesso de umidade, em geral, provoca decréscimo na germinação, visto que impede a penetração do oxigênio e reduz todo o processo metabólico resultante (NASSIF et al., 1998). Os resultados obtidos para C. alba estão de acordo com os apresentados pelos referidos autores, uma vez que o menor tempo de embebição (24 horas) acelerou o processo de emergência e para maior tempo de embebição (72 horas), houve redução na emergência das plântulas.

\section{CONCLUSÕES}

A escarificação mecânica não foi eficiente para acelerar a emergência das plântulas e a imersão das sementes de $C$. alba em água corrente por 24 ou 48 horas foi necessária para a superação da dormência em sementes dessa espécie.

\section{REFERÊNCIAS}

BRASIL. Ministério da Agricultura e Reforma Agrária. Regras para análise de sementes. Brasília: SNDA/ DNDV/CLAV, 1992. 365p.

BROSCHAT, T.K. Palm seed propagation. Acta Horticulturae. Jaboticabal, n.360, p.141-147, 1994.

CARVALHO, N. O. S., PELACANI, C. R., RODRIGUES, M. O. S., CREPALDI, I. C. 2005. Uso de substâncias reguladoras e não-específicas na germinação de sementes de licuri (Syagrus coronata (Mart.) Becc). Sitientibus. Feira de Santana, v.5, n. 1, p. 28 - 32, 2005.

FERREIRA, S.A. do N., GENTIL, D.F. de O. Extração, embebição e germinação de sementes de tucumã (Astrocaryum aculeatum). Acta Amazônica, Manaus, v. 36, n. 2, p.141-146, 2006.

KOBORI, N.N. Germinação, morfologia e sanidade de sementes de Livistona chinensis (Jack.) R. Br. Ex. Mart. (Arecaceae). 2006. 51f. Dissertação (Mestrado em Agronomia) - Faculdade de Ciências Agrárias e Veterinárias, Universidade Estadual Paulista, Jaboticabal, 2006.

LABORIAU, L.G. A germinação das sementes. Washington: Secretaria Geral da Organização dos Estados Americanos, 1983. 174p.

LORENZI, H., SOUZA, H.M., MEDEIROS-COSTA, J.T., CERQUEIRA, L.S.C., BEHR, N. Palmeiras brasileiras, exóticas e cultivadas. Nova Odessa, 2004. p.131.

MAGUIRE, J.D. Speed of germination-aid in selection and evaluation for seedling emergence and vigor. Crop Science, Madison, v.2, n.1, p.176-177, 1962.

MAPA. Ministério da Agricultura Pecuária eAbastecimento. Instrução Normativa $\mathrm{n}^{\circ} 19$, de 18 de outubro de 2005. Mantém as Regras para Análise de Sementes, edição 1992, aprovadas pela Coordenação-Geral de Apoio Laboratorial... Diário Oficial da União. Brasília, DF, 2005. Disponível em: <http://extranet.agricultura.gov.br/sislegis-consulta/ consultar legislação.do? operação=visualizar\&id=13594 >. Acesso em: 06 março 2008. 
NASSIF, S.M.L., VIEIRA, I.G., FERNADES, G.D. Fatores externos (ambientais) que influenciam na germinação de sementes. Informativo Sementes IPEF - Abril 1998. Disponível em: http://www.ipef.br/tecsementes/ germinacao.asp. Acesso em 23 de maio de 2010 .

PIVETTA, K.F.L., BARBOSA, J.G., ARAÚJO, E.F., DEMATTÊ, M.E.S.P. Propagação de palmeiras e estrelitzias. In: BARBOSA, J. G; LOPES, L. C. Propagação de plantas ornamentais. Viçosa, 2007. p. 43-70.

POTT, A., POTT, V. J. Plantas do pantanal. Empresa Brasileira de Pesquisa Agropecuária, Centro de Pesquisa Agropecuária do Pantanal. Corumbá, 1994. 320p.

QUEIROZ, M.H. Botão germinativo do palmiteiro (Euterpe edulis Mart) como indicador de germinação. Revista Brasileira de Sementes, Brasília, n. 2, p.55-59, 1986.

RIBEIRO JÚNIOR, J. I. Análises estatísticas no SAEG. Viçosa: UFV, 2001.

SAEG. SAEG: sistema para análises estatísticas, versão 5.0. Viçosa: UFV, 1993.
SILVA, J. S. V., ABDON, M.M., BOOCK, A., SILVA, M. P. Fitofisionomias dominantes em parte das sub-regiões do Nabileque e Miranda, sul do pantanal. Pesquisa Agropecuária Brasileira, Brasília, v.33, Número Especial, p.1713-1719, 1998.

SILVA, M. P., MAURO, R., MOURÃO, G., COUTINHO, M. Distribuição e quantificação de classes de vegetação do Pantanal através de levantamento aéreo. Revista Brasileira de Botânica, São Paulo, v.23, n.2, p.143-152, 2000.

StringuetA, A. C. O., AlveS, E. A., ARAÚJO, E. F., CARDOSO, A. A. Secagem e armazenamento de sementes de palmeira-real australiana (Archontophoenix alexandrae). Revista Brasileira de Armazenamento, Viçosa, v. 29, n. 1, p.51-57, 2004.

TAKAHASHI, L.S.A., ROCHA, J.N., SOUZA, J.R.P. Revisão sobre produção e tecnologia de sementes de espécies medicinais. Revista Brasileira de Plantas Medicinais, Botucatu, v.8, n. 4, p.198-209, 2006.

TOMLINSON, P.B. Anatomy of the monocotyledons. In: TOMLINSON, P. B. II Palmae. Oxford: C.R. Metcalf, p. 308-311, 1961.

Tabela 1. Porcentagem de emergência (\%E), tempo médio de emergência (TME) e índice de velocidade de emergência (IVE) de plântulas de Copernicia alba em função da escarificação

Table 1. Emergence percentage (EP), emergence averaget (EAT) and index of speed (IES) of Copernicia alba in function of the scarification

\begin{tabular}{cccc}
\hline Escarificação & $\mathbf{\%} \mathbf{E}$ & TME (dias) & IVE \\
\hline Testemunha & $64 \mathrm{a}$ & $56 \mathrm{a}$ & $0,22 \mathrm{a}$ \\
Escarificação no hilo & $66 \mathrm{a}$ & $56 \mathrm{a}$ & $0,22 \mathrm{a}$ \\
Escarificação no hilo e oposto ao hilo & $67 \mathrm{a}$ & $56 \mathrm{a}$ & $0,24 \mathrm{a}$ \\
CV (\%) & 18,08 & 7,76 & 18,02 \\
DMS (\%) & 13,05 & 4,8 & 0,05 \\
\hline
\end{tabular}

*Médias seguidas da mesma letra na coluna não diferem entre si pelo teste de Tukey a 5\% de probabilidade. 


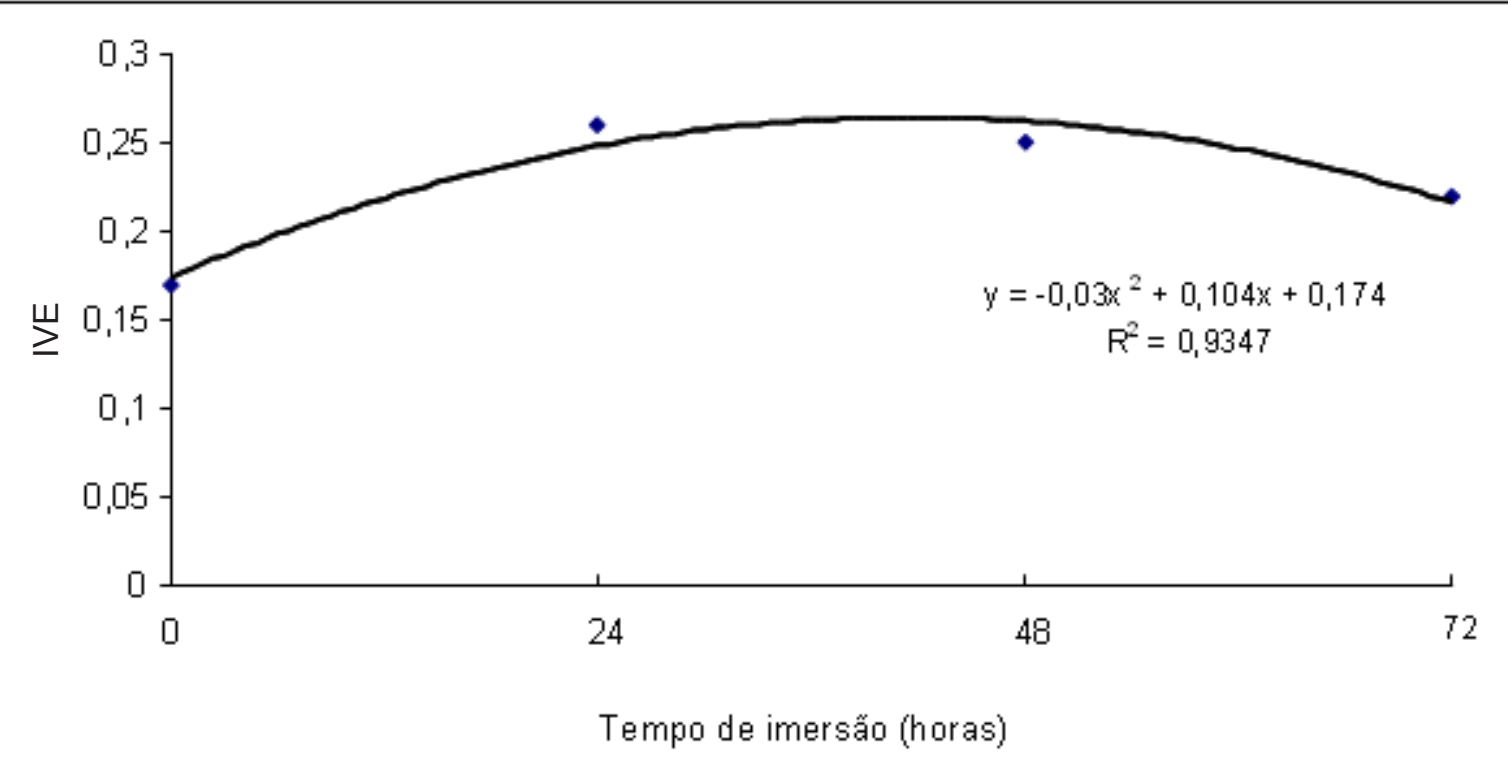

Figura 1. Índice de velocidade de emergência (IVE) de plântulas de Copernicia alba em diferentes tempos de imersão em água corrente.

Figure 1. Index of emergence (IES) of speed of Copernicia alba in different times of immersion in current water.

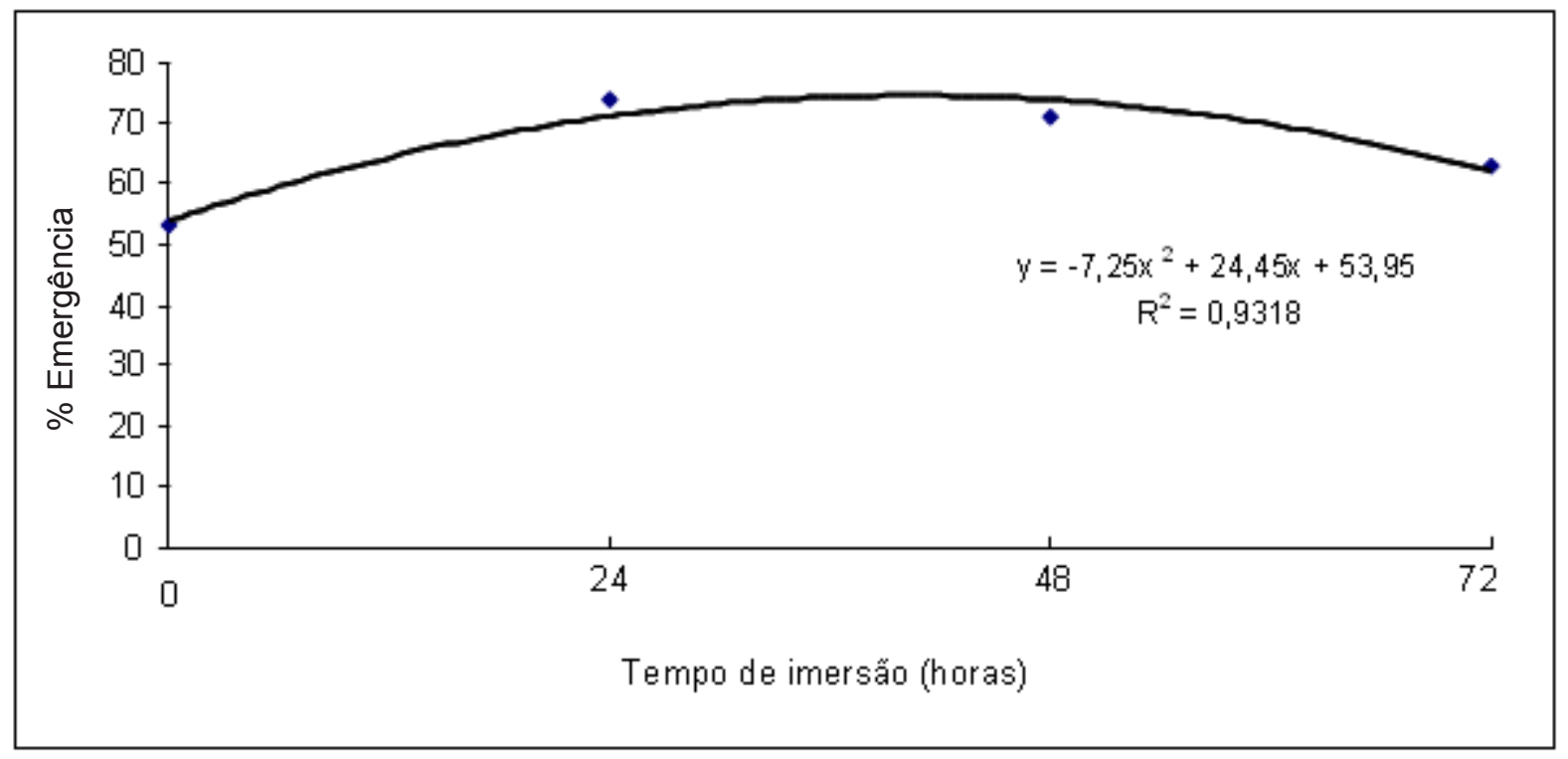

Figura 2. Porcentagem de emergência de Copernicia alba em diferentes tempos de imersão em água corrente.

Figure 2. Percentage of emergence of Copernicia alba seedlings in different times of immersion water. 